Frontiers in Heat and Mass Transfer

\title{
Editorial
}

\section{A TRIBUTE IN MEMORY OF PROFESSOR RALPH L. WEBB (1934 - 2011)}

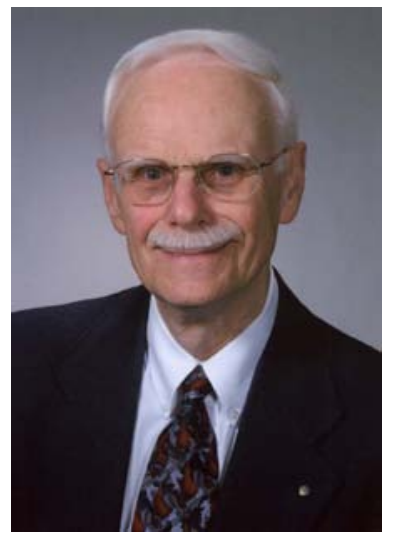

On April 3, 2011, Dr. Ralph L. Webb, Professor Emeritus of Mechanical Engineering at Pennsylvania State University, passed away in State College, Pennsylvania at the age of 77 . Dr. Webb made significant contributions in the field of enhanced heat transfer with applications in the areas of boiling, condensation, fouling, air-cooled heat exchangers, electronic equipment cooling, and forced convection for gases. In this editorial, we present to the thermal-fluids community some of the highlights of his life and career so that all can appreciate the true impact of his technical contributions.

Dr. Webb was born on February 22, 1934 to Grace and Kenneth Webb at the family's farm in Parker, Kansas. The family survived the Great Depression by relocating to Illinois, where Dr. Webb's father worked the oil fields. He graduated with honors from Kansas State University with a Bachelor of Science in Mechanical Engineering in 1957. Following graduation, Dr. Webb worked as an Engineering Maintenance Officer for the U.S. Air Force at the Nellis Air Force Base in Las Vegas, Nevada for two years. He earned his master's degree at Rensselaer Polytechnic Institute in New York in 1962. For the next 14 years, he was a Manager of Heat Transfer Research at The Trane Company in La Crosse, Wisconsin where he employed heat transfer enhancement technology to improve energy efficiency of airconditioning systems.

Dr. Webb received his Ph.D. degree from the University of Minnesota in 1969 under the direction of the late Professor Ernst R.G. Eckert, a renowned scientist in the field of heat and mass transfer who established the University of Minnesota as a world-class center of excellence in the field. Dr. Webb joined the Department of Mechanical Engineering at Pennsylvania State University as a professor in 1977 and became a professor emeritus in 2004. He taught academic courses in two-phase heat transfer, heat exchanger design, enhanced heat transfer, and applied heat and mass transfer. He is the author of the book Principles of Enhanced Heat Transfer and Editor-in-Chief of the Journal of Enhanced Heat Transfer. He published over 275 papers in the general area of heat transfer enhancement, and has eight U.S. patents on enhanced heat transfer surfaces. During his tenure, Dr. Webb guided 49 master's and 17 doctoral students to graduation. He was
Executive Manager of Thermal Management at Omega Piezo Technologies in State College, Pennsylvania from 2003 to 2007.

Dr. Webb performed research in various aspects of enhanced heat transfer and heat-exchanger design, including electronic equipment cooling, and advanced heat exchange technology for gases and liquids, boiling, and condensation. Much of this research involved enhanced heat transfer surface technology. He also developed several computer programs for the practical design of heat exchangers, including automotive radiators, brazed aluminum evaporators and condensers, cooling towers, and shell-and-tube exchangers.

Dr. Webb received many national and international honors and awards, including the AIChE Donald Q. Kern Award, the ASME Heat Transfer Memorial Award, and the U.K. Refrigeration Institute HallThermotank Gold Medal. He was also a Life Member and Fellow of ASME and a Fellow of ASHRAE.

Dr. Webb was one of the founding editorial board members of Frontiers in Heat and Mass Transfer (FHMT) and Thermal-FluidsPedia. His paper entitled "Heat Exchanger Design Methodology for Electronic Heat Sinks" was accepted for publication by FHMT shortly before his death and we are pleased to include his paper in this issue. To the heat transfer community, he will be missed as a remarkable and generous gentleman. His significant contributions to thermal-fluids community will be with us forever. May his soul rest in peace and his spirit live on among all of us.

Amir Faghri
Professor, University of Connecticut
Editor-in-Chief of Frontiers in Heat and Mass Transfer
Email: faghri@engr.uconn.edu
Yuwen Zhang
Professor, University of Missouri
Editor-in-Chief of Frontiers in Heat and Mass Transfer
Email: zhangyu@missouri.edu

Amir Faghri tiers in Heat and Mass Transfer Eriers in Heat and Mass Transfer 